\title{
Usability Engineering for GIS: Learning from a Screenshot
}

\section{Mordechai (Muki) Haklay and Antigoni Zafiri}

\author{
Department of Civil, Environmental and Geomatic Engineering, University College London (UCL), Gower St. \\ London WCIE 6BT \\ Email: m.haklay@ucl.ac.uk
}

In this paper, the focus is on the concept of Usability Engineering for GIS - a set of techniques and methods that are especially suitable for evaluating the usability of GIS applications - which can be deployed as part of the development process. To demonstrate how the framework of Usability Engineering for GIS can be used in reality, a screenshot study is described. Users were asked to provide a screenshot of their GIS during their working day. The study shows how a simple technique can help in understanding the way GIS is used in situ.

Keywords: Usability Engineering, Human-Computer Interaction, GIS, snapshot study

\section{INTRODUCTION}

Interest in Human-Computer Interaction (HCI) has been part of Geographical Information Science (GIScience) for a long time. Long before the term GIScience was coined (Goodchild, 1992), and even before the term Geographical Information System (GIS) was invented (Tomlinson, 1967), researchers of 'Man Machine Interaction' at MIT were utilising the display capabilities of the latest generation of computers to manipulate oceanic geographical information though, admittedly, the visualisation that was possible in the early 1960s was of rudimentary points on a display monitor (Pivar et al., 1963). From this early start, HCI became an integral part of the GIScience research agenda.

After a flurry of interest in the mid 1990s in the way common users, those that use GIS every day as part of their working life, use these systems (Traynor and Williams, 1995; Davies and Medyckyj-Scott, 1996), HCI research in GIScience changed its emphasis. Today, the range of topics covered by HCI research in GIScience includes deeper understanding of spatial cognition (Mark et al., 1999), development of novel interfaces (Blaser et al., 2000), and ontology in spatial data (Fonseca et al., 2000) among others. This is a natural progression in a discipline which established itself some 15 years ago with Goodchild's seminal definition of the field as 'Geographic Information Science', followed by a concerted intellectual effort to define a coherent research agenda (Rhind, 1998; Goodchild, 1992; Mark, 2003; McMaster and Usery, 2004). Indeed, three areas which are central in the GIScience research agenda are related to HCI: spatial cognition, spatial ontologies, and geographic visualisation (Geovisualisation).
While this current body of research is highly significant in advancing the knowledge in Geographical Information Science and is influential in the development of GIS practice in many ways, it seems that, in the process, the common user has been neglected, almost forgotten. There is lack of research into the way GIS is used at the workplace, in schools, and at home. Moreover, the context and use of GIS has changed dramatically since the studies of the early 1990s and, today, the common user is one of the million or so people across the globe who works daily with GIS software, or one of the tens of millions of users who uses public mapping sites - such as Google Maps or MapQuest or uses digital geographical information in other forms, such as through Satellite Navigation Systems (Longley et al., 2001). We know very little about these users, and how to design systems for them in a way that ensures that GIS is used effectively, efficiently, and enjoyably.

Significantly, the early studies, such as those that are included in Medyckyj-Scott and Hearnshaw (1993) or Nyerges et al. (1995), focused on GIS use by engineers, draughtspersons, and scientists - specialised users who work in an environment where tasks are well defined and the function of the system is fairly clear. Today, the range of users has changed dramatically in terms of educational attainment, the tasks which they perform, and the organisational settings within which GIS is used. Furthermore, GIS itself has changed significantly. When Davies and Medyckyj-Scott (1996) conducted their research, GIS was mainly command-line driven and run on UNIX workstations, whereas current systems rely on Graphical User Interface (GUI), large databases, and the Internet.

It is, therefore, somewhat ironic that, just as GIS became more commonplace at work and at home, there has been 


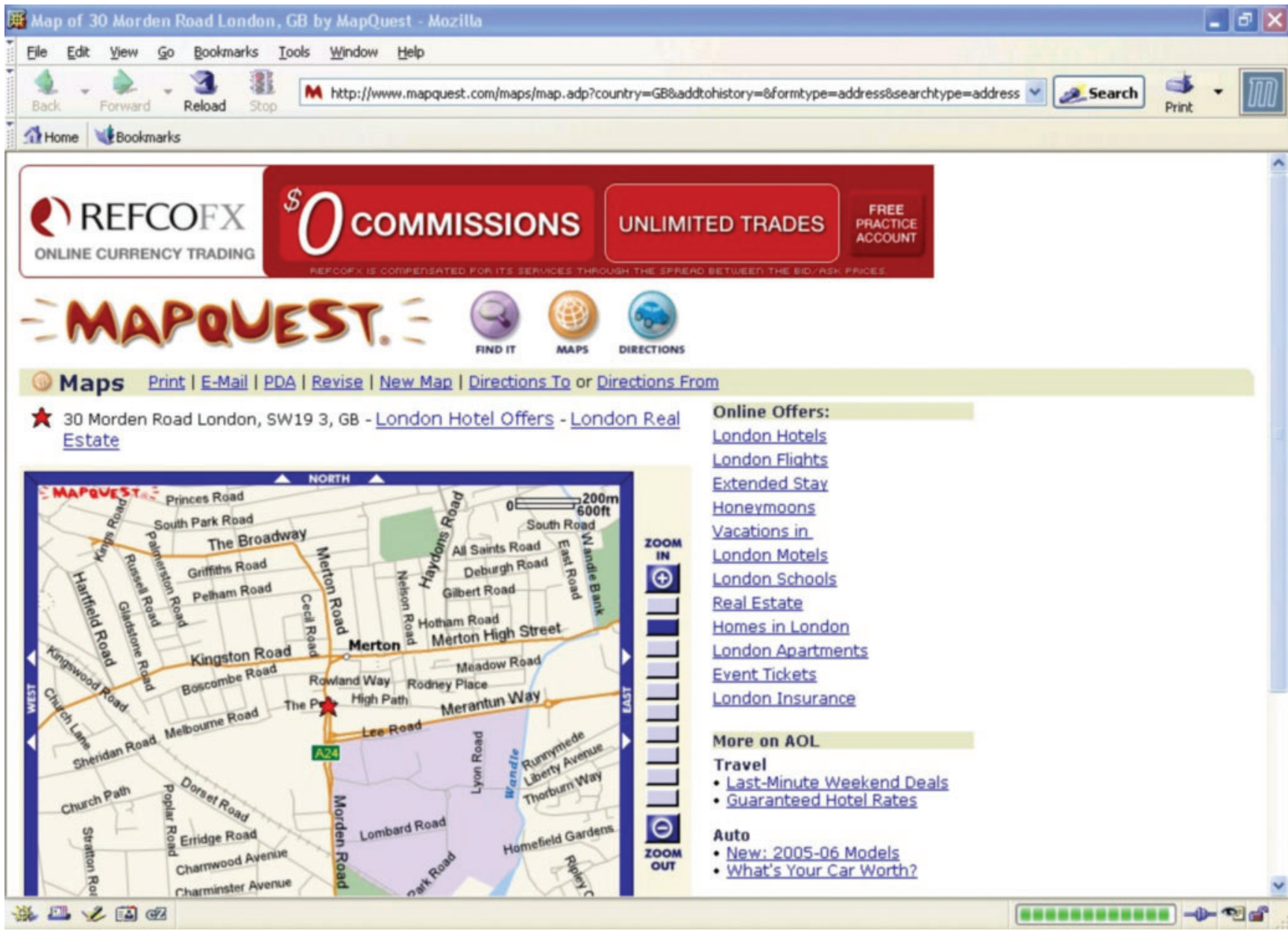

Figure 1. MapQuest interface mid 2005 (Source: Skarlatidou 2005)

almost no research looking at how GIS is used in these environments. For example, while web mapping sites have been in existence since 1994 (Putz, 1994), to our knowledge Skarlatidou and Haklay (2006) is the first published study in which public mapping sites were compared in terms of their performance with users who are GIS novices (see also Nivala, 2007, Steinmann, 2004). The study included 30 users, and examined 8 popular web mapping sites. The study has highlighted that, even in commercial sites where the revenue is generated by visitors and therefore it is imperative to ensure that the sites are usable and accessible, there are many usability problems. A significant number of users ( 1 in 5 ) failed to perform fundamental tasks on the sites - even though, clearly, the sites were designed to support these tasks.

Beyond the specific aspects of public mapping websites, the study also emphasised the need for researching the 'common user' or 'accidental geographers' as Unwin (2005) calls them. It is very likely that some of the websites that were included in the study went through usability testing and evaluation by their developers - but the outcomes of such studies are not made public, and cannot be used by developers of new systems. Furthermore, the study demonstrates that, by understanding the way common users approach public mapping sites, meaningful observations that are relevant to any application of GIS can be gleaned.

For example, the study highlighted the size of the map as one of the most important elements within the factors that influence the efficiency of the performance of a task with the system. In the study, users were given an address and were asked to locate the nearest underground station. The distance between the address and the station was selected in such a way that the user needed to pan the map to find the station, and hence provided an evaluation of the panning and zooming capabilities of the site. The results showed a significant variation - between an average of 0.15 clicks with Google Maps to 5.45 clicks in MapQuest, which translates to an average time of about 3 s to complete the task in Google, compared with over $40 \mathrm{~s}$ with MapQuest. While these differences cannot be wholly attributed to the size of the map as a proportion of the total interface (see Figures 1 and 2), the research raised the question about the impact of the map size on the overall usability and productivity of these websites as well as desktop GIS.

The outcomes of the neglect to study common users and improve basic GIS software (either online or in a desktop environment) are actually familiar to the GIScience research community, as many within it are teaching GIS to new 


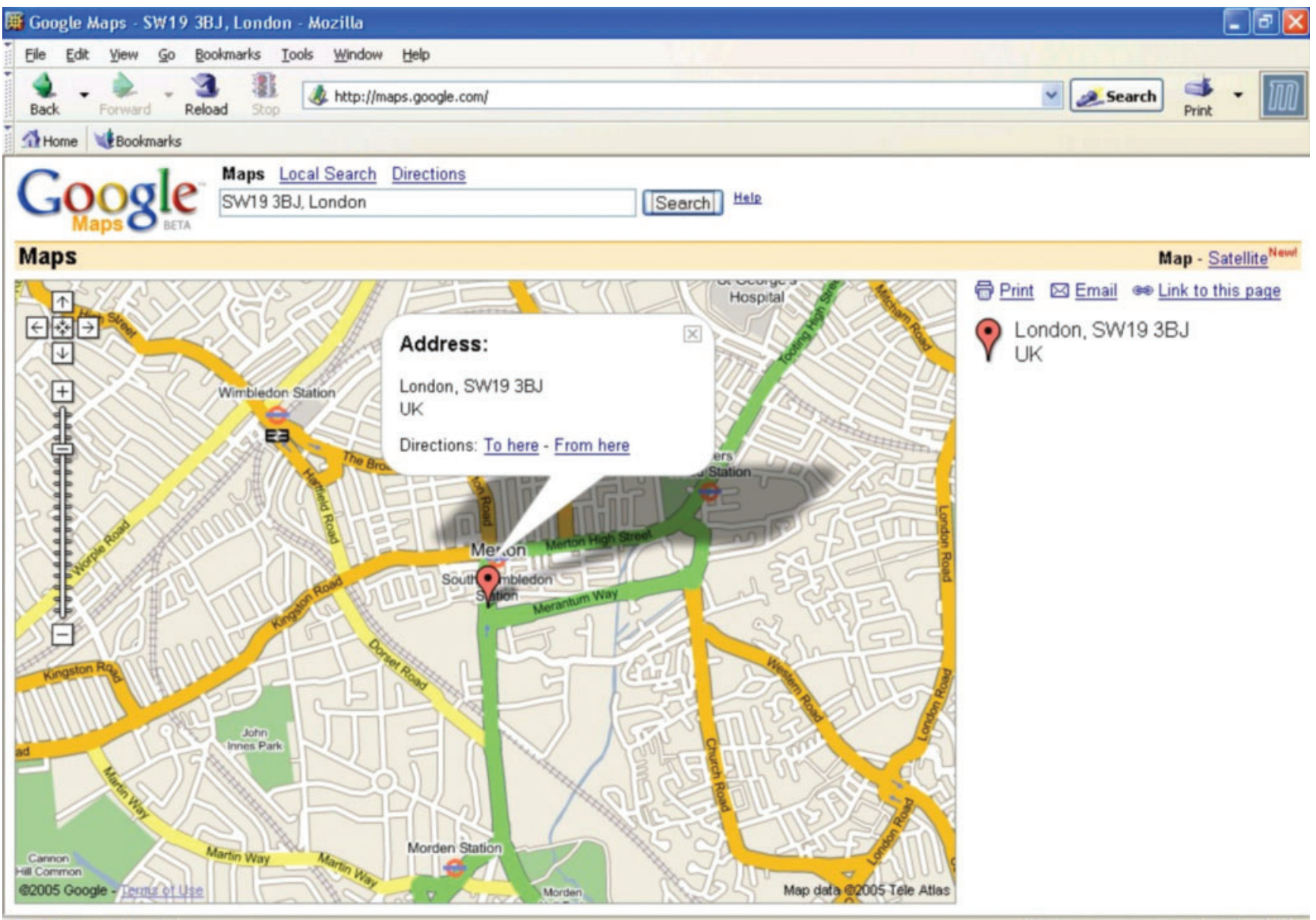

it)

Figure 2. Google Map interface mid 2005 (Source: Skarlatidou 2005)

generations of students. During computer practicals, it is hard not to notice the difficulties that students are facing in learning to operate popular GIS packages. Clearly, a systemic failure in ensuring the usability of these packages is occurring. It is astonishing that, although written over a decade ago, Traynor and Williams (1995) 'Why are Geographic Information Systems Hard to Use?' is still accurate, and current.

\section{IS USABILITY ENGINEERING FOR GIS THE SOLUTION?}

As Geographic Information and GIS methods are becoming more and more popular, there is a need to create an interest within the GIScience research community in general, and those that focus on HCI in particular, in the needs of common users.

This can be achieved by focusing attention on the development of Usability Engineering for GIS. Usability Engineering (UE) is a sub-discipline of HCI which emerged in the mid 1980s with the aim of addressing 'system usability in a reliable and replicable manner. UE provides systematic methods and tools for the complex task of designing user interfaces that can be readily comprehended, quickly learned, and reliably operated.' (Butler, 1996, p. 59.) UE built on the lessons learned through HCI research, and turned them into a set of operational procedures, matrices, and techniques that can be used by system designers and developers to ensure that the system is efficient, effective, engaging, error tolerant, and easy to learn (also known as the 5 Es of Usability - although UE literature offers many other lists and conceptualisations).

Importantly, Usability Engineering techniques have been widely used as part of HCI research in GIScience: examples include Haklay and Tobón (2003), where UE techniques were used within a Public Participation GIS context, or Fabrikant (2001), where they served to study the scale metaphor in information visualisation. There are also examples from GIS practitioners who are using UE in the design of new systems (Ellis et al., 2003). Moreover, in the area of Geovisualisation, an ongoing interest and use of UE for evaluating new interfaces and configurations is commonplace (Koua and Kraak, 2004; MacEachren et al., 2005; Marsh, 2007).

However, despite this cumulative knowledge in the use of UE as part of GIS research, there is no coherent body of UE knowledge for GIS - knowledge that can be applied in the development of new systems, or how best to use UE within GIScience studies. UE for GIS should include tools and methods that have been designed or adapted in such a way that they take the special characteristics of geographical information and its manipulation into account, and assist in 
the design of user interaction. Noteworthy is that the most popular textbook on GIS (Longley et al., 2001) only mentioned HCI in passing, and the most complete treatise of HCI in a GIS textbook (Worboys and Duckham, 2005) dedicates less than a page to UE. A recent literature review revealed over 150 papers and book chapters discussing the use of UE methods as part of GIScience and GIS research but only a few that can be categorised as UE for GIS (such as Marsh, 2007; Nivala, 2007; and Harrower and Sheesley, 2005).

Usability Engineering for GIScience can be immensely valuable to the developers of GIS. UE will provide a set of tried and tested methods that have been proven to be effective for GIS. This can be done quite easily through two activities. Firstly, by consolidating the lessons that were learned from the use of UE techniques as part of GIScience research, a basic body of knowledge can be assembled including methods and matrices that have been found to be the most useful for GIS designers and developers. Secondly, by developing UE research for GIS and focusing on the design of specific UE techniques which will take into account the special characteristics of GIS such as the size of the map or the representation of the information (see also Davies et al., 2005).

By developing a focus on Usability Engineering for GIS, GIScience research can rekindle the interest in the common user and, due to the widespread availability of modern GIS, make a real impact and improve the quality of the working life of millions.

Of course, Usability Engineering for GIS must recognise the differences between the range of users of GIS and geospatial technologies. Techniques that are suitable for evaluating public web mapping sites will not necessarily be suitable for experienced desktop GIS users. However, as Unwin (2005) noted, the GIScience research community knows very little about the characteristics, needs, skills, and context of these users, be they 'Google Earth browsers' who enjoy using a geobrowser at home or experts who work with GIS on a daily basis.

To clarify the concept of Usability Engineering for GIS, a practical example of a technique that was developed at UCL in 2005 is provided. The technique is based on a screenshot study and is aimed at more experienced users than in the web-mapping study described earlier. Here, we are interested in users of desktop GIS who are employed to operate these software packages during their working day. The aim here is to demonstrate how, by taking into account the specific characteristics of GIS and the user environment, it is possible to devise suitable UE methods and techniques.

\section{DEVELOPING A USABILITY EVALUATION METHOD}

There are several methods available for evaluating the usability of an interface. Their aim is to change one or more measures of usability in order to attain increased usability (Nielsen, 1993). While a comprehensive discussion of the methods is beyond the scope of this paper, it is worth mentioning the range of techniques, which include Heuristic evaluation, Guideline reviews, Pluralistic walkthroughs, Consistency inspections, Standards inspections,
Cognitive walkthroughs, Formal usability inspections, and Feature inspections (for more details, see Nielsen, 1993).

Perhaps the approach used most often since its introduction in the 1980s is usability testing (Shneiderman, 1998; Dix et al., 2004). It is based on the principle of trailing prototypes, analysing data captured about the system and user performances (Lin et al., 1997). Often laboratories are used for user observation (Nielsen, 1993; Dix et al., 2004), and information can be derived from the execution time, accuracy, and users' satisfaction as well as video and system logs (Lin et al., 1997). Because real users are actively involved, the approach can be more objective, and reveal serious and recurring problems (Lin et al., 1997).

Questionnaires are also used to accompany usability tests. They can be used at any stage of the development and they are used to assess the perception of the users about a system (Shneiderman, 1998; Chien, Diehl and Norman, 1988; Dix et al., 2004). Their main advantage is that they are inexpensive and they can yield a large number of responses as opposed to usability testing. Furthermore, the users' satisfaction of a system is a critical measure for its acceptance and can be independent of the system's performance measure (Chien, Diehl and Norman, 1988).

All usability evaluation methods have their advantages and disadvantages, and, generally, they can be either difficult to apply or largely dependent upon the evaluator's experience (Chien, Diehl and Norman, 1988). The aim of the screenshot study, however, was not to carry out a formal usability evaluation of a particular GIS, but to compare the effectiveness of the interface across the different GIS packages, to derive conclusions and make recommendations that can lead to increased usability of GIS design in general. Therefore, the questionnaire approach was chosen as a preferred method of evaluation. In order to gain an understanding in the way the GIS interface is actually used in practice, users were asked to provide a screenshot of their entire screen while they were in the middle of their work with GIS. The questionnaire was used to support the screenshots and provide additional information about the users and their tasks.

The questionnaire was emailed to GIS mailing lists, asking users to take a screenshot of their GIS, paste it into their email client, answer the questionnaire, and send it back to UCL for analysis. This was a short procedure that required no more than $5 \mathrm{~min}$ of attention from the users.

The screenshots constitute the primary means of collecting the essential information and achieving the objective of this study. Most importantly, they provide a more objective measure for assessing the usability of the GIS interface and they can be combined and correlated to the subjective measures derived from the questionnaire. The correlation between the two measures will help to examine and better understand the relation between the objective and subjective information (Hornbæk, 2006).

\section{THE SCREENSHOT STUDY}

As noted, the aim of the study was to explore how the GIS interface was used when carrying out routine tasks. Our core question was about the way in which GIS users organise and customise the interface of their system. 
Percentage of users finding the interface logical

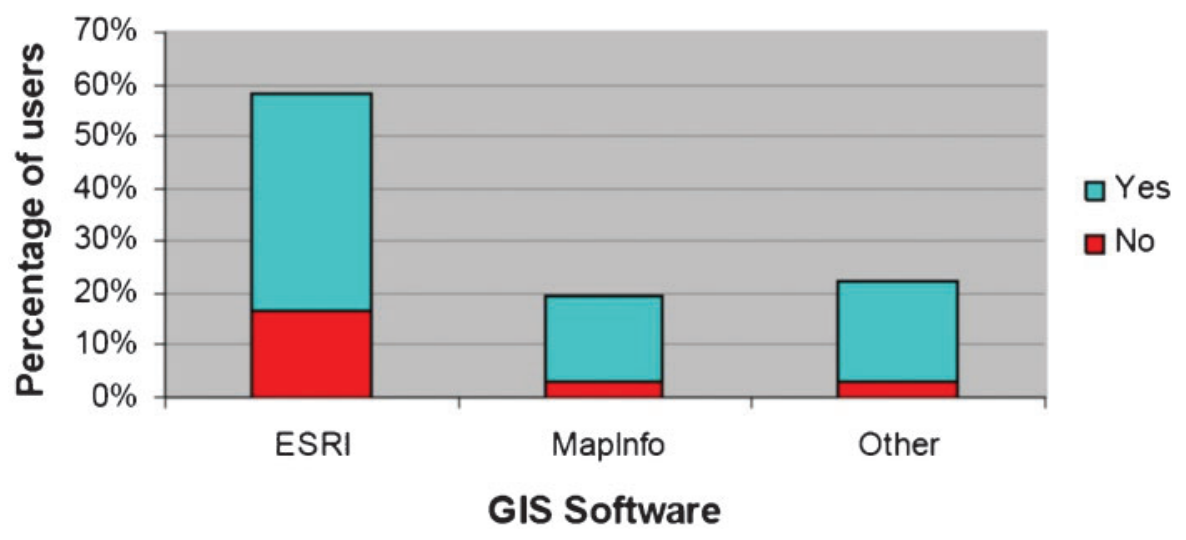

Figure 3. Percentage of users who find the interface logical

In a Graphical User Interface (GUI) environment, the user is capable of changing the size of windows in a given application, setting toolbars, and organising certain aspects of the interface. The use of the GUI creates tension between the integration of User Interface (UI) elements, which are used to drive the application and perform tasks, and the available area for the actual application (Kurtenbach et al., 1997). As noted, the web mapping study indicated that the size of the map area as a proportion of the total interface can have significant implications of the effectiveness of the application. Yet, the ability to customise the interface means that the user is capable of reducing the effective area of the map. It is, therefore, interesting to explore how GIS users organise their interface, taking into account the graphical nature of the information that is being manipulated, and the way it changes during routine operation through zooming and panning operations.

An ideal methodology for such a study, as described in Davies and Medyckyj-Scott (1996), includes the identification of the organisation and users that will be involved in the study, followed by a selection of a representative sample from all applications and systems in which the GIS is used, and the same task should be tested across all applications in order to be able to draw a comparison. However, such a comprehensive study is complex and requires significant resources. Furthermore, at the general level of GIS tasks and users, it is very difficult to define a specific range of applications and processes.

However, although the screenshot method is simpler and easy to complete, it is interesting to explore how effective it is in revealing usage patterns and comparison amongst the different GIS. Although the nature of this study was exploratory, a set of research questions were formulated to focus the analysis and to enable us to draw a more comprehensive picture and conclusions. First, the study allowed us to explore 'How is the map area used?' - as noted above, this was one of the core motivations for this study. An observation from a previous study (Skarlatidou and Haklay, 2006) indicated that, in almost all tasks, a larger map area reduced the time length of basic tasks on a web mapping site. Further anecdotal evidence from observations of how novice users use GIS (in other words - how students operate popular GIS packages during their studies) provided further impetus for this question. To put the first question in context, a further question was formulated: 'What proportion of the interface is assigned to the map area and to other parts of the interface such as toolbars?' Other questions that could be answered by examining screenshots were 'What can we learn about the way in which users customise their GIS interface?' and 'Do they tend to use the windows tiled or overlapping?' This is important in considering which model of windows organisation is the most suitable for GIS.

Since the screenshot was accompanied by a short survey, which provided some information about their experience with GIS, it was also possible to explore 'Is there any difference between experienced and inexperienced users in the way they use their GIS?'

Finally, the images themselves provided information about the resolution of the monitor that was being used, and it was possible to explore 'What screen resolutions are generally used by GIS users?'

\section{RESULTS}

Following the research questions, an analysis of the 35 images that were received ensued. Each image was analysed using a standard graphics package (such as Adobe Photoshop or Paint.Net). The following aspects of the images were recorded - the total size of the image, which indicated the screen resolution that was used during the capture process; the number of toolbars on the interface and whether they were active or not; the size of the area of the interface that was dedicated to the map; the type of software that was used; and the number of concurrent applications that were running.

Once all the results were tabulated, it was possible to calculate the percentage of the total screen area that was dedicated to the map and to other interface elements. Statistical analysis was carried out to evaluate correlations between users' demographic profiles and the image characteristics.

The finding of the study revealed the following traits of the GIS users who were in our sample group: the majority 
The average map area of the GIS interface as a percentage of the screen/interface total area

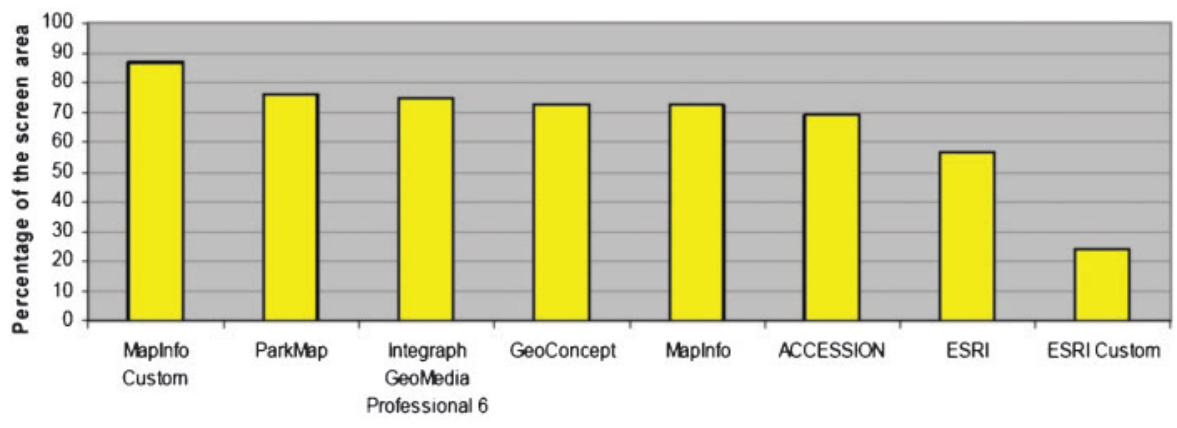

GIS software

Figure 4. Map area as percentage of the interface

of the users $(60 \%)$ that took part in the study were experienced GIS users and had been using GIS for over a year with some of them using it for over 10; they were technically competent and declared that they feel comfortable with computer use; they were using a GIS on a regular weekly basis with the majority using it between $2-10$ hours $(39 \%)$ and $10-30$ hours $(25 \%)$.
Similarly, about $75 \%$ of the users stated that they had no difficulty locating desired functions on the GIS interface and found its structure logical, although quite a few experienced users reported that this was due to the rearrangement of the toolbars. As Figure 3 demonstrates, ESRI products scored low on the logical structure of the interface; the majority of the users still use GIS mainly for

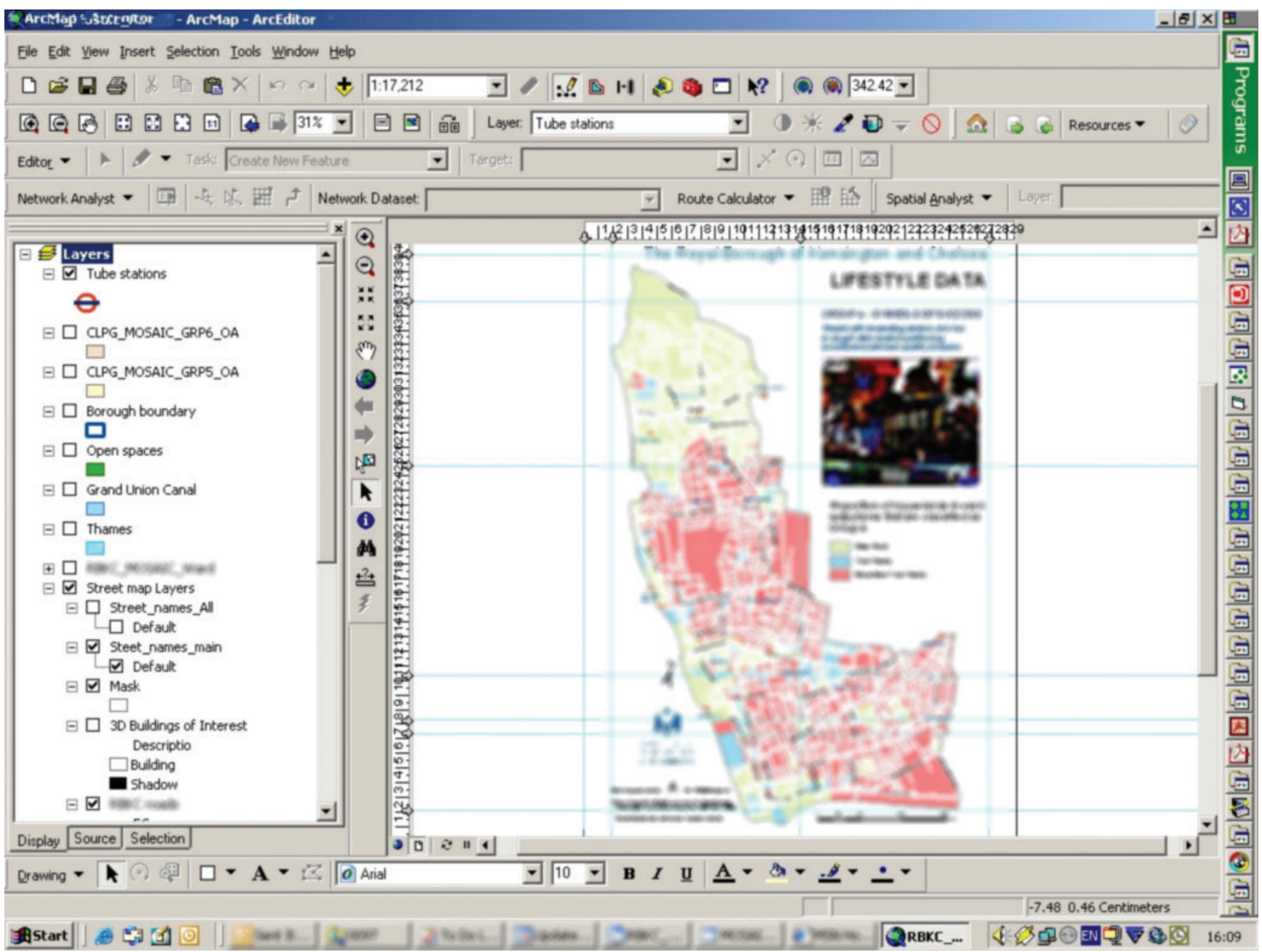

Figure 5. Sample ArcMap Screenshot (1) 


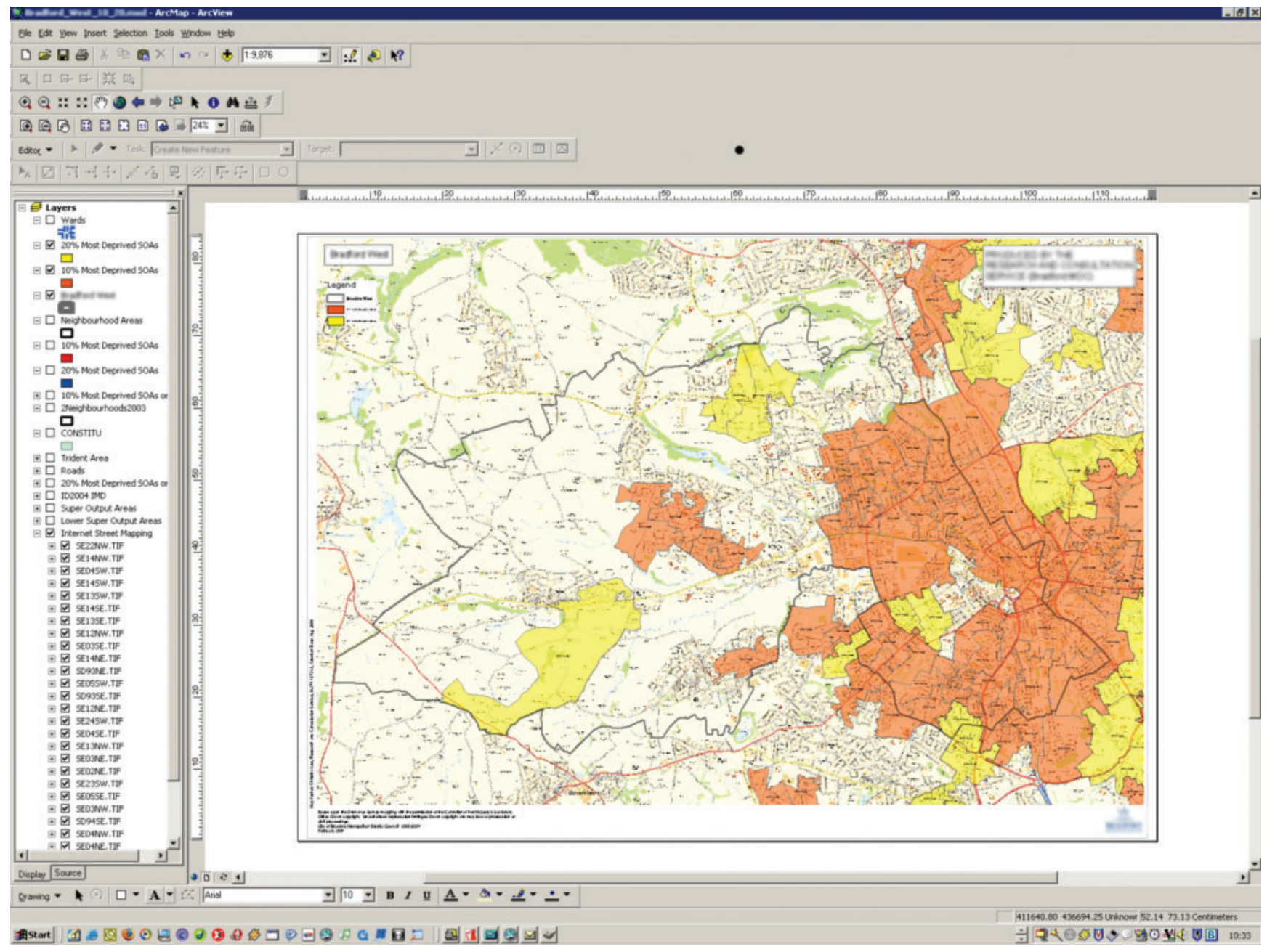

Figure 6. Sample ArcMap Screenshot (2)

displaying and managing data, thematic mapping, querying, and for basic types of analysis and basic geo-processing.

The screenshots themselves showed that GIS users seem to use high-resolution screens $-1280 \times 1024$ pixels or greater. This is expected, as the application is graphic oriented. However, this is above average for other computer applications - for example, when compared with statistics from the site W3Schools.com, which provide an indication of resolutions that are used in the web design sector.

As noted, the map area of the GIS interface is the most important part of the interface for the user. However, the area available to the map area represents, on average, a mere $70 \%$ of the total screen area of the interface, while this figure can drop down to half and even a quarter of the interface's area in a few cases. ESRI products were found to allow for the smallest available space of the interface to the map area - an average of $56 \%$. The layers window occupies an important part of the interface, especially for ESRI products, sacrificing the area available to the map area. Figure 4 shows the distribution of the map area as a proportion of the interface.

Further observations are provided from the analysis of the actual screenshots (Figures 5-8).
The results of our findings are that, in most cases, GIS users are sacrificing the map area in order to accommodate other parts of the interface (Figure 5, 6, 7). Notice how, in Figure 2, the user has docked many toolbars to the upper part of the interface, three of which are inactive. Clearly, there is large area of the interface that does not contribute to user productivity. In Figure 7, the ArcToolbox element of the interface is consuming a large amount of the 'screen asset'.

Furthermore, in Figure 5, the user has four inactive toolbars. As noted, inactive toolbars can be seen in Figures 6 and 7 , too. This high number of inactive toolbars, which was also observed in novice users, is surprising. The principle behind the design of toolbars is that they are designed to allow the users to control the number and positions of the toolbars, so that 'users who wish to conserve screen space for their workspace can eliminate the toolbars' (Shneiderman and Plaisant, 2005, p. 274). Therefore, why do ArcMap users keep their toolbars docked even when they are not contributing to the current task? A possible hypothesis is that, due to the fact that users find the ArcMap interface lacking in consistency, they dock the toolbar as a way to remind themselves about certain functions and how they can be accessed (see Figure 9). This hypothesis requires further evaluation and investigation. 


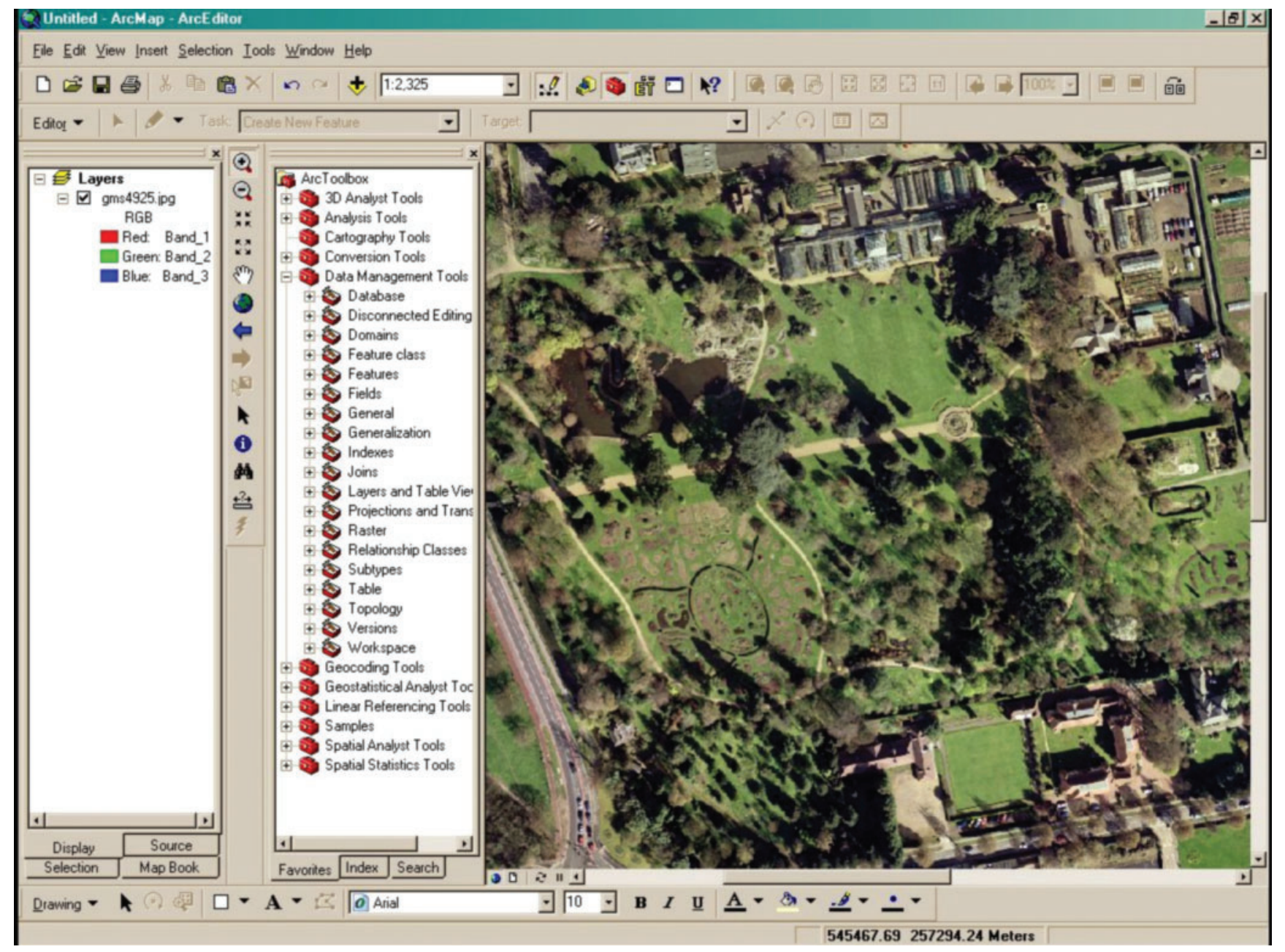

Figure 7. Sample ArcMap Screenshot (3)

As for the use of tiled or overlapping windows, as expected the map window is always maximised - even when the user is using more than one map (Figure 8), they are organised so as to use the maximum space of the screen.

Apart from a weak correlation between the level of experience of users and the size of the screen in pixels, no correlation was found between inactive toolbars and experience or the size of the map and the number of hours the user spent using GIS. This might be due to the small sample and is an area that should be explored in future screenshots studies.

In general, the results are very encouraging for such a simple method with paucity of information provided by the users. Further details and results are available in Zafiri (2006).

\section{CONCLUSIONS}

The screenshot study has demonstrated that it is possible, even with paucity of information, to learn about GIS users and their tasks. The method provided some insights into the screen size that is being used, the organisation of the GIS interface, and other aspects of the work environment of common GIS users. A larger study is needed to improve the methods and to explore aspects such as the scale of the map that is used, the tasks that are performed, or the number of layers that are commonly used by GIS users.

The screenshot study is not a replacement for the traditional, detailed usability studies. It can be used in cases where information about the user's GUI environment is useful in the design process. A screenshot study is easy to administer and analyse and, as such, provides a suitable technique for usability evaluation of GIS packages. As shown, it is particularly suitable for GIS, where the graphical information is so significant and where much can be learned from the analysis of the screenshot.

This type of study is very suitable for designers of desktop and Internet-based applications who want to understand their users' current pattern of use, screen size, practice of using tiled windows, and many other aspects. While it is true that some aspects can be investigated by using weblogs - for example, by coding a web-GIS application to record the scale - this type of analysis does not give the full context of the user's environment such as which toolbars are used in the web browser or which other applications are running at the same time. This can be very useful for a GIS software vendor to understand how the potential users of a future 


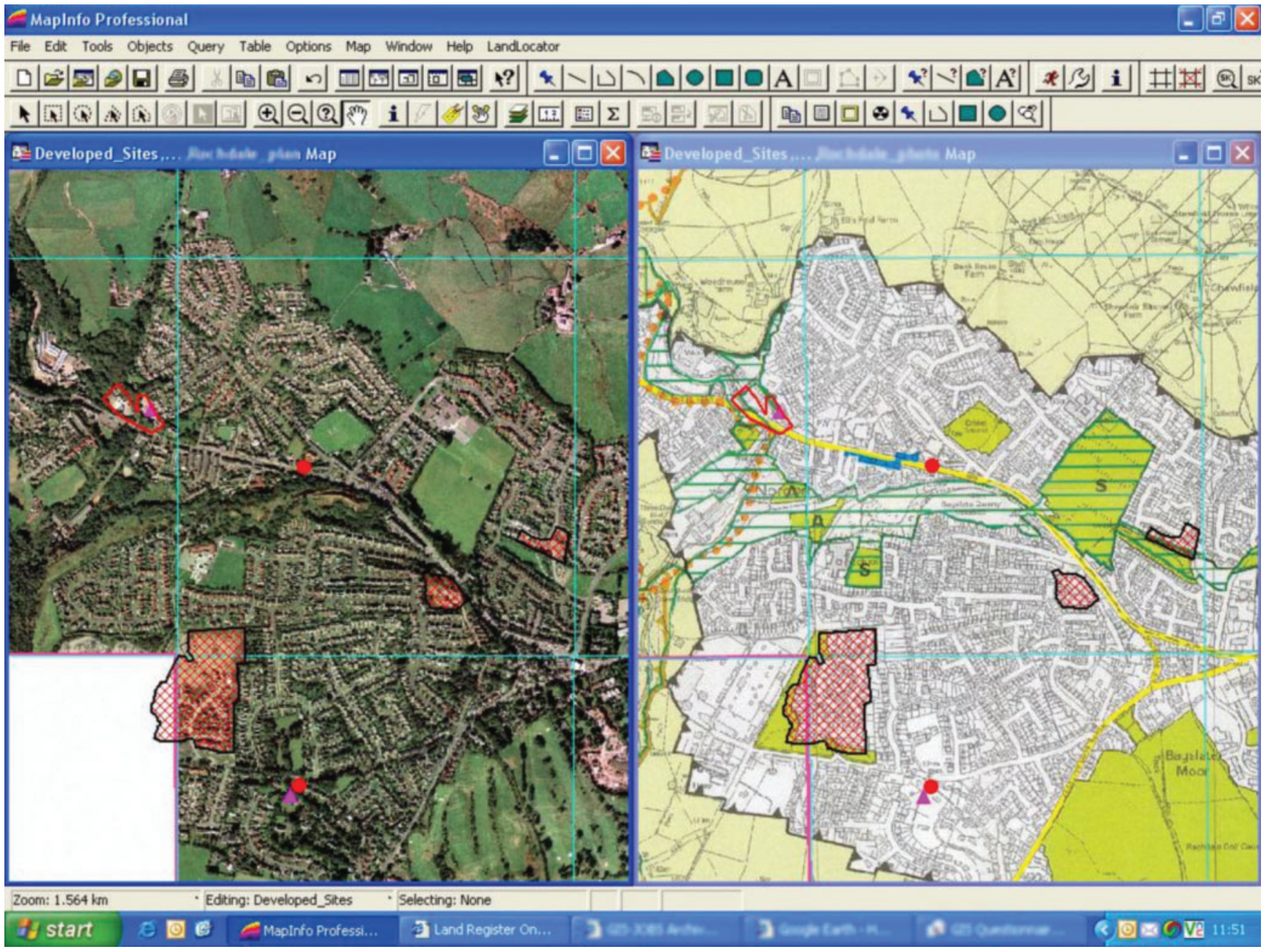

Figure 8. Sample Mapinfo Screenshot

product are currently using their GIS. It can also be used to understand what users do with the software and what the characteristics of their work environment are.

The questionnaire that accompanies the screenshot is also significant as, unlike other studies, it is completed during the working day and can be used to capture some of the perceptions of the users while they are performing their daily tasks.

Turning back to the issue of Usability Engineering for GIS, the study demonstrated that, when taking the specific

\section{Average toolbar activity}

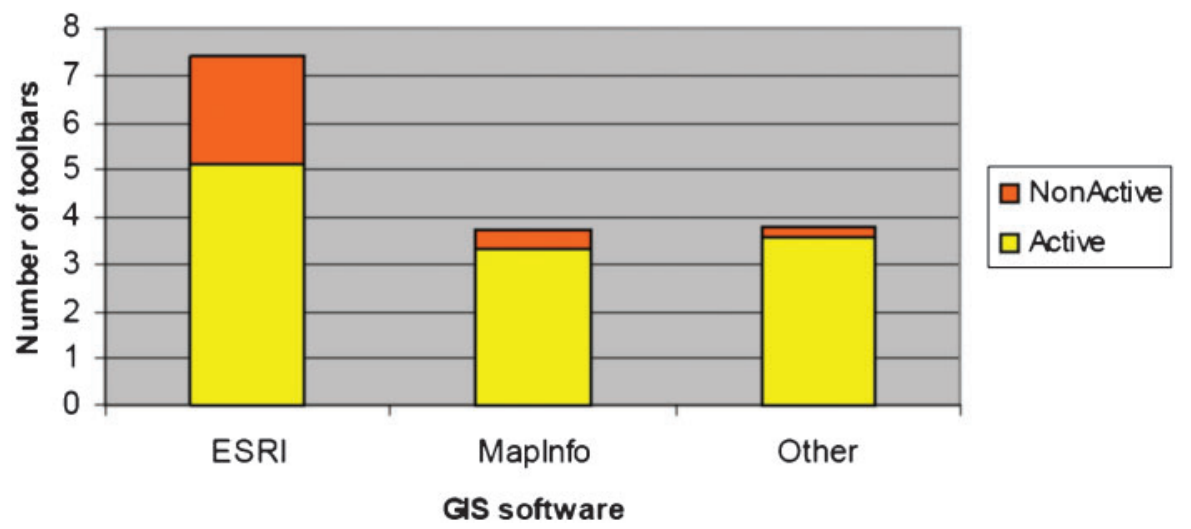

Figure 9. Average toolbar activity across applications 
characteristics of a GIS working environment, it is possible to develop fast and cheap methods for the analysis of the users' environment. The study has demonstrated the scope of Usability Engineering for GIS and the potential of developing techniques and methodologies within this domain. Similar studies, such as Harrower and Sheesley (2005) or Marsh (2007), can also be seen as part of Usability Engineering for GIS. The technique that was tested in the study is suitable for the framework of Usability Engineering for GIS as suggested above - it relates to the use of GIS in practice, and can involve any user of a GIS or mapping package; as noted, it can be integrated within a routine software development process, either at an early stage of information gathering for understanding users' requirements, or as part of post-deployment evaluations and improvements.

\section{BIOGRAPHICAL NOTES}

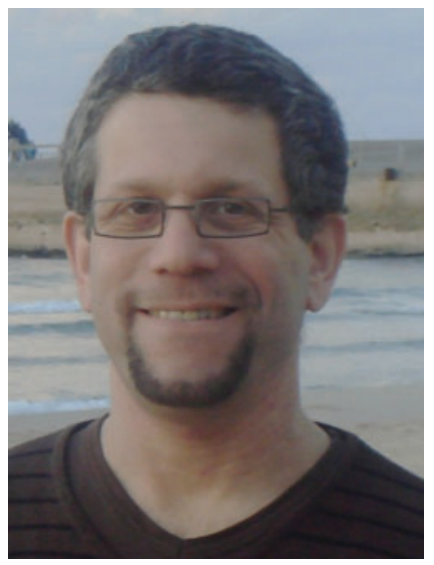

Dr Muki Haklay is a Senior Lecturer in GIS at UCL, where he is also the director of UCL Chorley Institute an interdisciplinary research centre, with an aim to spatially enable UCL strategic research activities. Dr Haklay was the course director of the University of London MSc in GIScience between 2002 and 2006 and continues to teach on this programme and other programmes in the department.

He has been researching HCI and usability aspects of GIS since 1997 and has published several papers on this topic. His research interests include Public access and use of Environmental Information; Human-Computer Interaction (HCI) and Usability Engineering aspects of GIS; and Societal aspects of GIS use.

$\mathrm{He}$ is particularly interested in the use of GIS by various audiences and the combination of GIS with other Computer Mediated Communication (CMC) tools.

\section{ACKNOWLEDGEMENT}

The snapshot study described here was carried out by Antigoni Zafiri in her MSc dissertation at UCL in 2005, and the web-mapping usability study was carried out by Artemis Skarlatidou in her MSc dissertation at UCL in 2005. The author would like to thank the comments of two anonymous reviewers.

\section{REFERENCES}

Blaser, A., M. Sester and M. Egenhofer (2000) 'Visualisation in an early stage of the problem-solving process in GIS', Computer and Geosciences, 26(1), 57-66.
Butler, K. A. (1996) 'Usability Engineering turns 10', Interactions, $3(1), 59-75$.

Chien, J. P., V. A. Diehl and K. L. Norman (1988) 'Development of an Instrument Measuring User Satisfaction of the HumanComputer Interface', Proceedings CHI'88, Human Factors in Computing Systems, ACM, 213-218.

Davies, C. and D. Medyckyj-Scott (1996) 'GIS Users Observed', International Journal of Geographical Information Systems, $10(4), 363-384$.

Davies, C., L. Wood and L. Fountain (2005) 'User-centred GI: hearing the voice of the customer' Paper presented at: AGI '05: People, Places and Partnerships, Annual Conference of the Association for Geographic Information, London, UK, 8-10 November 2005. (London: Association for Geographic Information)

Dix, A., J. Finlay, G. D. Abowd and R. Beale (2004) HumanComputer Interaction, 3rd ed. Pearson Education Limited: Harlow, England.

Ellis, C.D., C. Quiroga, S.Y. Shin and R.J. Pina (2003) 'GIS and Human-centered Systems Design: Using Ethnographic Data Collection and Analysis Methods to Design a Utility Permitting Support System', URISA Journal 15.

Fabrikant, S. I. (2001) 'Evaluating the Usability of the Scale Metaphor for Querying Semantic Information Spaces'. In: Spatial Information Theory: Foundations of Geographic Information Science. Conference on Spatial Information Theory (COSIT '01), Lecture Notes in Computer Science 2205, Montello D. R. (ed.), Springer Verlag, Berlin, Germany, 156-171.

Fonseca, F., M. Egenhofer, C. Davis, and K. Borges (2000) 'Ontologies and Knowledge Sharing in Urban GIS', Computer, Environment and Urban Systems, 24(3), 232-251.

Goodchild, M. F. (1992) 'Geographical information science', International Journal of Geographical Information Systems, $6(1), 31-45$.

Haklay, M. and C. Tobón (2003) 'Usability evaluation and PPGIS: towards a user-centred design approach', International Journal of Geographical Information Science, 17(6), 577-592.

Harrower, M. and B. Sheesley (2005) 'Designing Better Map Interfaces: A Framework for Panning and Zooming', Transactions in GIS, 9, 77-89.

Hornbæk, K. (2006) 'Current Practice in Measuring Usability: Challenges to Usability Studies and Research', International Journal of Human-Computer Studies, 64, 79-102.

Koua, E.L. and M.-J. Kraak (2004) 'A Usability Framework for the Design and Evaluation of an Exploratory Geovisualisation Environment ${ }^{*}$ Eighth International Conference on Information Visualisation (IV'04) IEEE Computer Society, $153-158$.

Kurtenbach, G., G. Fitzmaurice, T. Baudel and B. Buxton (1997) 'The design of a GUI paradigm based on tablets, two-hands, and transparency'. In Proceedings of the SIGCHI Conference on Human Factors in Computing Systems (Atlanta, Georgia, United States, March 22-27, 1997). S. Pemberton, Ed. CHI '97. ACM Press, New York, NY, 35-42.

Lin, X. H., Y-Y. Choong, and G. Salvendy (1997) 'A Proposed Index of Usability: A Method for Comparing the Relative Usability of Different Software Systems', Behaviour and Information Technology, 16(4/5), 267-278.

Longley, P. A., M. F. Goodchild, D. J. Maguire and D.W. Rhind (2001) Geographic Information Systems and Science, John Wiley \& Sons, London.

MacEachren, A. M., A. Robinson, S. Hopper, S. Gardner, R. Murray, M. Gahegan and E. Hetzler (2005) 'Visualizing geospatial information uncertainty: What we know and what we need to know'. Cartography and Geographic Information Science 32, 139-160.

Mark D. M., C. Freksa, S. C. Hirtle, , R Lloyd, and B. Tversky (1999) 'Cognitive models of geographical space', International Journal of Geographical Information Science, 13(8), 747-774.

Mark, D. M. (2003) 'Geographic information science: Defining the field' In Foundations of Geographic Information Science, ed. M. Duckham, M. F. Goodchild, and M. F. Worboys, 3-18. New York: Taylor and Francis

Marsh, S. L., (2007) Using and Evaluating HCI Techniques in Geovisualisation: Applying Standard and Adapted Methods in 
Research and Education. Unpublished $\mathrm{PhD}$, City University, London.

McMaster, R. B. and E. L. Usery (2004) A Research Agenda For Geographic Information Science, CRC Press.

Medyckyj-Scott, D. and H. M. Hearnshaw (Eds.) (1993) Human Factors in Geographical Information Systems, Bellhaven Press, London.

Nielsen, J. (1993) Usability Engineering, Academic Press, Boston, MA.

Nivala, A-N. (2007) Usability Perspectives for the Design of Interactive Maps, publications of the Finnish geodetic institute No. 136.

Nyerges, T. L., D. M. Mark, R.Laurini and M. J. Egenhofer (Eds.) (1995) Cognitive Aspects of Human-Computer Interaction for Geographic Information Systems, Kluwer Academic Publishers, Dordrecht.

Pivar, M., E. Fredkin, and H. Stommel (1963) 'Computer-compiled oceanographic atlas: an experiment in man-machine interaction', Proceedings of the National Academy of Sciences of the United States of America 50(2), 396-398.

Putz, S. (1994) 'Interactive Information Services Using World-Wide Web Hypertext' Proceedings of the First International Conference on World-Wide Web, Geneva, May 25-27, 1994.

Rhind, D.W. (1988) 'A GIS research agenda', International Journal of Geographical Information Systems, 2, 23-28
Shneiderman, B. (1998) Designing the User Interface: Strategies for Effective Human-Computer Interaction. (3rd ed). Addison Wesley Longman, Inc.

Shneiderman, B., and C. Plaisant (2005) Designing the User Interface, $4^{\text {th }}$ ed., Pearson Education, Boston, USA.

Skarlatidou, A. and M. Haklay (2006) 'Public Web Mapping: Preliminary Usability Evaluation', Proceedings of GIS Research UK Conference, Nottingham, April 5-7 2006.

Steinmann, R., A. Krek and T. Blaschke (2004) 'Analysis of Online Public Participatory GIS Applications with Respect to the Differences Between the US and Europe', Proceedings of Urban Data Management Symposium '04, Chioggia, Italy.

Tomlinson, R. F. (1967) An Introduction to the Geographic Information System of the Canada Land Inventory. Department of Forestry and Rural Development, Ottawa Canada.

Traynor, C. and M. G. Williams (1995) 'Why are Geographic Information Systems Hard to Use?', CHI'95 Mosaic of Creativity, Denver, Colorado, ACM/SIGCHI, 288-289.

Unwin, D. (2005) 'Fiddling on a different planet', Geoforum, 36, 681-684

Worboys, M. and M. Duckham (2005) GIS: A Computing Perspective, 2ed. Boca Raton, FL: CRC Press.

Zafiri, A.F. (2006) The effectiveness of WIMP for GIS users: a snapshot study for assessing the usability of current GIS, unpublished MSc dissertation, UCL. 